\title{
Long-Term Performance of Hybrid Anodes for Cathodic Protection of Reinforced Concrete
}

\author{
Wayne Dodds ${ }^{1, *}$, Christian Christodoulou ${ }^{1}$, and Chris Ian Goodier ${ }^{2}$ \\ ${ }^{1}$ AECOM, Colmore Building, 20 Colmore Circus Queensway, Birmingham, UK, B4 6AT \\ ${ }^{2}$ School of Architecture, Building \& Civil Engineering, Loughborough University, Leicestershire, UK, LE11 3TU
}

\begin{abstract}
The long-term performance of hybrid anode corrosion protection systems (UK invention disclosed in Patent GB2426008B) was investigated on six bridge structures as part of a holistic approach to corrosion risk management, using the performance criteria in ISO BS EN 12696:2016. The aim of the study was to review the effectiveness of current design approaches to meet the residual service life when the anodes are operating in the galvanic phase. This was achieved by analysing data on the general condition of the structures, the ongoing performance of the installed hybrid anodes, and assessing the subsequent corrosion risk. It was found that the six structures were generally in good condition, 1 to 8 years after refurbishment works, with low associated corrosion risk in areas protected by the hybrid anode systems. This is a positive finding for the wider implementation of hybrid anode systems as an alternative corrosion management technique. The reinforcement in the protected areas remained predominately in a passive condition, with calculated corrosion rates below the ISO 12696:2016 recommended threshold of $2 \mathrm{~mA} / \mathrm{m}^{2}$.
\end{abstract}

\section{Introduction}

\subsection{Hybrid corrosion protection technology}

Cathodic protection (CP) of reinforced concrete structures is a well-established method of preventing the initiation of, and arresting ongoing, corrosion. The hybrid corrosion protection system is a discrete zinc anode system that is installed into pre-drilled cavities within reinforced concrete (Figure 1). Hybrid technology combines both an impressed and galvanic system to arrest ongoing corrosion and prevent future initiation.

The hybrid anodes are manufactured using $18 \mathrm{~mm}$ Zinc cylinders, ranging from $42 \mathrm{~mm}$ to $220 \mathrm{~mm}$ in length, with an integrated titanium connector wire. A coating is applied to the surface of the anode to keep the anode active throughout its design life (Figure 2).

Initially, the system is connected to a temporary, constant 9V DC power supply, typically for a period of at least one week, depending on the type of reinforcement (e.g. mild steel or prestressed), to deliver a charge to the reinforcing steel [1-5]. This initial impressed treatment phase re-passivates the reinforcement by means of generating a reservoir of alkali at the steel concrete interface and is achieved by passing a minimum of $50 \mathrm{kC}$ of charge per metre squared of steel surface area [5-9]. Applied charge densities of this magnitude have been shown to change the environment at the steel leading to the arrest of the corrosion process $[6,7,9]$. The hybrid anode is then disconnected from the temporary DC power supply and connected directly to the steel reinforcement, creating a galvanic cell, similar to a battery. This latter treatment phase continues for the remainder of the anodes' working life and provides a relatively low current to the steel reinforcement to maintain steel passivity [3, 10-13].

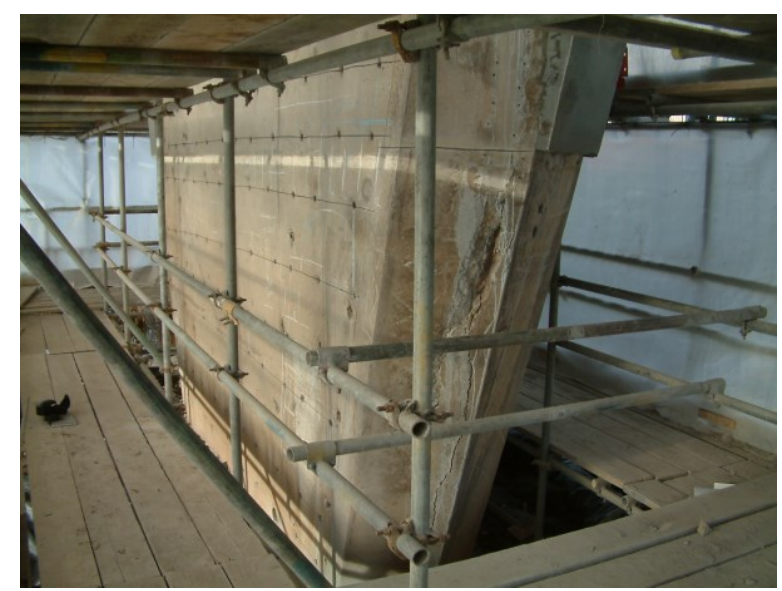

Fig. 1. Hybrid anode installation on reinforced concrete bridge pier

* Corresponding author: Wayne.Dodds@aecom.com 


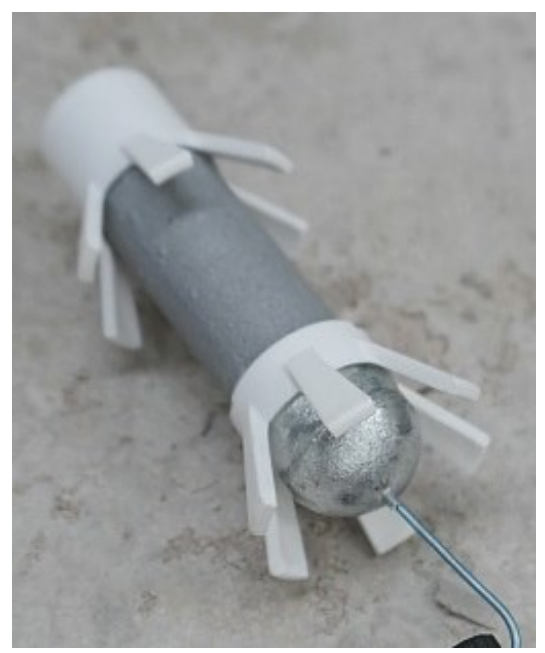

Fig. 2. Typical hybrid anode

The hybrid technology offers the same advantages of a galvanic system, in that little or no maintenance is required throughout its design life cycle, and no permanent power supply needs to be installed as part of the works; while also packing the corrosion arrest power traditionally associated with a full ICCP system [1, 3-5]. The system can be designed to enable an additional impressed treatment phase (e.g. an additional $50 \mathrm{kC} / \mathrm{m}^{2}$ of steel surface area to be implemented at a later stage in the structures life if any corrosion activity is detected through monitoring); which does not impact on the remaining design life. Hybrid anodes are typically designed to provide a residual service life of $30-50$ years [14].

\subsection{Performance evaluation}

The performance criteria for cathodic protection systems is defined in ISO 12696:2016 and requires a positive depolarisation shift of steel potential by $100 \mathrm{mV}$ over a period of 24 hours or a depolarisation greater than $150 \mathrm{mV}$ more over an extended period of time [15]. This potential shift has been empirically developed over time and later adopted within the ISO standard as an absolute value. Research into the behaviour of galvanic and hybrid systems has shown that the $100 \mathrm{mV}$ potential shift is not always achieved in benign environments and when the risk of corrosion has been reduced by the anode system itself $[3-4,11]$. It is for this reason that ISO 12696:2016 acknowledges that a holistic approach to the overall condition and corrosion risk assessment of the structure may be adopted for hybrid and galvanic anodes, such as corrosion rates, with values less than $2 \mathrm{~mA} / \mathrm{m}^{2}$ indicating passive steel [15].

The corrosion rate can be determined from an established mathematical model, the Butler-Volmer equation, using the applied current $\left(\mathrm{i}_{\text {appl }}\right)$, the potential shift $(\Delta \mathrm{E})$ and predicted values for the anodic and cathodic Tafel slopes $\left(\beta_{\mathrm{a}}\right.$ and $\beta_{\mathrm{c}}$ ) (Eqn. 1). A corrosion rate of this magnitude $\left(2 \mathrm{~mA} / \mathrm{m}^{2}\right)$ equates to a steel section loss of approximately $1 \mathrm{~mm}$ over 500 years, which is a particularly stringent value for a reinforced concrete structure that has a service life of 50-100 years.

$$
i_{c o r r}=\frac{i_{a p p l}}{\left(\exp \left(\frac{2.3 \Delta E}{\beta_{c}}\right)-\exp \left(-\frac{2.3 \Delta E}{\beta_{a}}\right)\right)}
$$

A falling trend in the steel corrosion rate combined with a rising trend in steel potential is also a sign that steel passivity is being achieved [15].

Hybrid anodes' current tends to fluctuate with the changing risk of corrosion initiation, commonly referred to as the 'responsive behaviour' [10]. This has resulted to some concerns within industry as to the accuracy of designs to meet the residual service life when the anodes are operating within the galvanic phase.

The aim therefore was to determine the effectiveness of hybrid anode systems in real-life structures at providing sufficient protection against the initiation of corrosion, in order to examine their long-term performance using a holistic condition and corrosion risk assessment as described by ISO 12696:2016 [15].

To achieve this, six bridge structures on which hybrid corrosion protection systems were installed around the UK between 2006 and 2013, in varying locations and climatic conditions, were examined, including:

a) Laverock Hall, Newcastle, Tyne and Wear

b) Whiteadder, Berwick, Northumberland

c) Storth Lane, South Normanton, Derbyshire

d) Kyle of Tongue, Achuvoldrach, Highland

e) M69 Junction 2, Huncote, Leicestershire

f) Paston Interchange, Peterborough, Cambridgeshire

\section{Methodology}

A desk study was initially conducted including a review of previous principal inspection reports, existing monitoring data, and as-built drawings, where available. Each structure was visually inspected to determine the condition of the reinforced concrete structures and to confirm details of both the structure and the installed hybrid anode system.

Steel potential readings were recorded before and after a 24 hour depolarisation period, where possible. Corrosion rates were subsequently calculated by means of the polarisation resistance method to determine the effectiveness of the hybrid systems in preventing the initiation of corrosion. The Butler-Volmer equation (Eqn. 1) is an established method of calculating corrosion rates from depolarisation data and has previously been used to report on the performance of cathodic protection systems $[1-2,4,11,16]$. The anodic $(\beta a)$ and cathodic $(\beta \mathrm{c})$ Tafel slopes were set at $120 \mathrm{mV}$ [11].

The corrosion rate for each of the structures was assessed against the criteria for cathodic protection systems as laid out in ISO 12696:2016 [15]. Where 
possible, the change in corrosion rates was also assessed against the trend of steel 'on' potential.

\section{Analysis of Results}

Overall, the six bridge structures were found to be in good condition following refurbishment works with minor site specific defects as summarised in Table 1. As the hybrid systems were installed at different times between 2006 and 2013, the extent of record monitoring data varies. The authors acknowledge that limited corrosion rate data is available for some of the structures and a more detailed record would be useful. The calculated corrosion rates and subsequent corrosion risk assessments are summarised for each structure below.

Table 1 Summary of structure condition surveys

\begin{tabular}{|c|c|}
\hline Structure & Notes \\
\hline $\begin{array}{l}\text { (a) Laverock } \\
\text { Hall }\end{array}$ & $\begin{array}{l}\text { No visible defects were noted to the } \\
\text { reinforced concrete piers. Water staining } \\
\text { was observed at high level indicating that } \\
\text { the bridge joints are still leaking. }\end{array}$ \\
\hline (b) Whiteadder & $\begin{array}{l}\text { No visible defects were noted to the } \\
\text { reinforced concrete piers. Water and rust } \\
\text { staining observed on the piers from the } \\
\text { primary steel girders due to water ingresses } \\
\text { through the deck joints. }\end{array}$ \\
\hline (c) Storth Lane & $\begin{array}{l}\text { Significantly more water ingress was } \\
\text { observed on the South abutment compared } \\
\text { to the North abutment. No defects were } \\
\text { noted within the area of influence of the } \\
\text { hybrid CP system. }\end{array}$ \\
\hline $\begin{array}{l}\text { (d) Kyle of } \\
\text { Tongue }\end{array}$ & $\begin{array}{l}\text { No signs of corrosion were found. Repairs } \\
\text { to prestressed beams were generally in } \\
\text { good condition with no evidence of } \\
\text { delamination or spalling. No faults were } \\
\text { identified with the hybrid CP system } \\
\text { (Glass et al, 2008; Holmes et al, 2011a). }\end{array}$ \\
\hline $\begin{array}{l}\text { (e) M69 } \\
\text { Junction } 2\end{array}$ & $\begin{array}{l}\text { No signs of corrosion were found. Small } \\
\text { amounts of water ingress were observed } \\
\text { from the carriageway above across all three } \\
\text { abutments. No defects were noted within } \\
\text { the area of influence of the hybrid CP } \\
\text { system. }\end{array}$ \\
\hline $\begin{array}{l}\text { (f) Paston } \\
\text { Interchange }\end{array}$ & $\begin{array}{l}\text { No signs of corrosion were found. No } \\
\text { defects were noted within the area of } \\
\text { influence of the hybrid CP system. Water } \\
\text { ingress was observed from the carriageway } \\
\text { above. }\end{array}$ \\
\hline
\end{tabular}

\subsection{System a): Laverock Hall}

The corrosion rate for the pier beam has generally remained significantly below the $2 \mathrm{~mA} / \mathrm{m}^{2}$ recommended value for passive steel (Figure 3). On two occasions, a higher corrosion rate was measured for the pier column; however, this has since reduced back below the threshold value, showing that the anode has responded to the risk of corrosion initiation. The two occasions where the corrosion rate increased above the $2 \mathrm{~mA} / \mathrm{m}^{2}$ threshold does not necessarily indicate a non-compliant system. The corrosion rate calculated at these two occasions equates to a reinforcing steel section loss of approximately $3.5 \mathrm{~mm}$ and $2.2 \mathrm{~mm}$ respectively, over a period of 1000 years, which is considered to be structurally negligible.

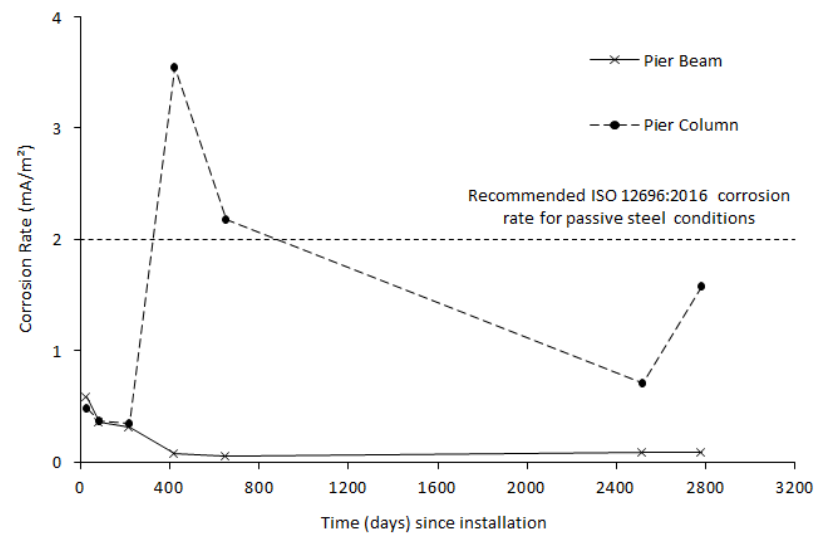

Fig. 3. Change in corrosion rate with time

Furthermore, a review of the steel 'on' potential values, indicates that generally they have increased over time which suggests overall steel passivity (Figure 4).

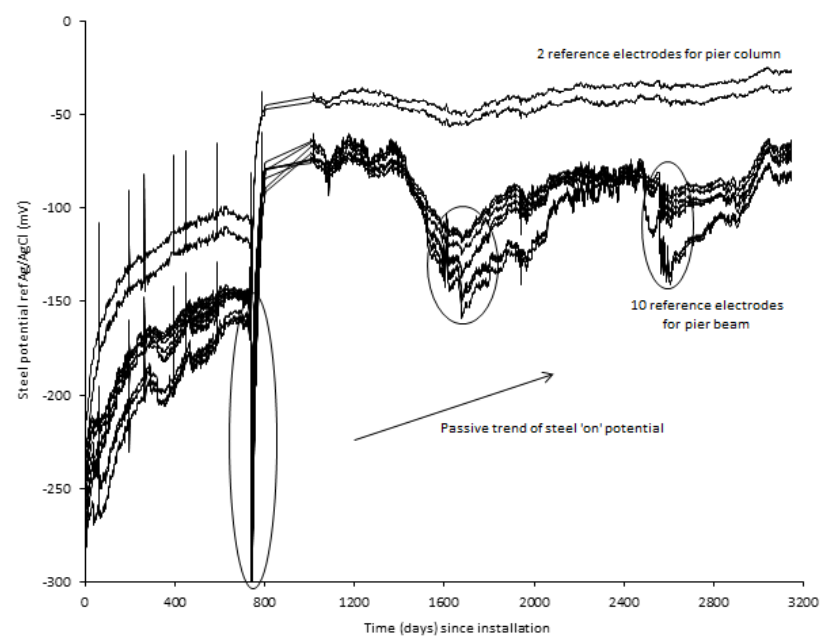

Fig. 4. Change in steel 'ON' potential with time

The sudden changes in 'on' potential readings observed at approximately 750, 1700 and 2550 days (identified in Figure 4) can be associated with changes in the environmental conditions due to wetting of the piers from the carriageway above. In these instances, the hybrid anodes have responded effectively by providing a higher current to overcome the increased risk of corrosion [10].

\subsection{System b): Whiteadder}

The value of corrosion rate for the upper anode zone has remained below the threshold value of $2 \mathrm{~mA} / \mathrm{m}^{2}$ since the 
installation of the hybrid system in 2007 , indicating that the steel has remained passive. In contrast, the values for the lower anode zone have fluctuated with time (Figure $5)$.

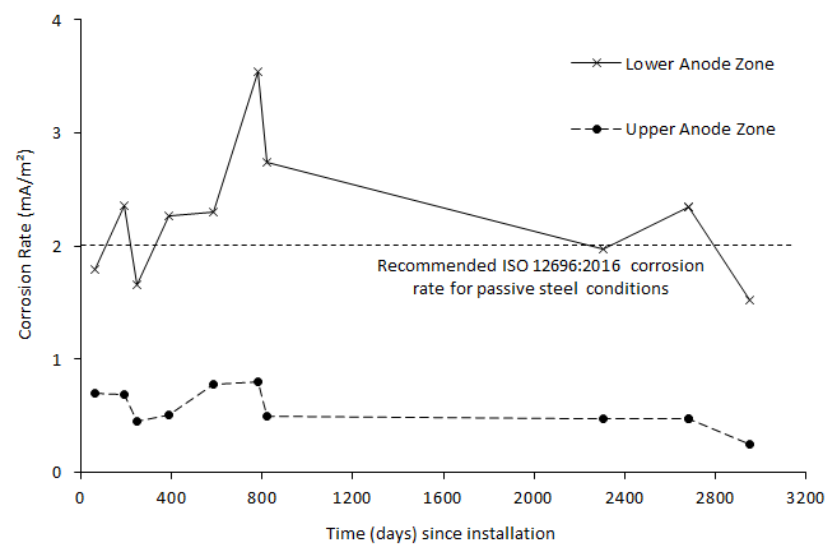

Fig. 5. Change in corrosion rate with time

The corrosion rate for the lower anode zone has largely remained above the recommended threshold. The maximum corrosion rate calculated since installation is $3.5 \mathrm{~mA} / \mathrm{m}^{2}$ which equates to a reinforcing steel section loss of approximately $3.5 \mathrm{~mm}$ over a period of 1000 years, which is again considered to be negligible when compared to a 120 year design life of a bridge structure.

The passivity of steel reinforcement for both zones is confirmed by the fact that the steel 'on' potential has been increasing towards move positive values for all monitored areas (Figure 6).

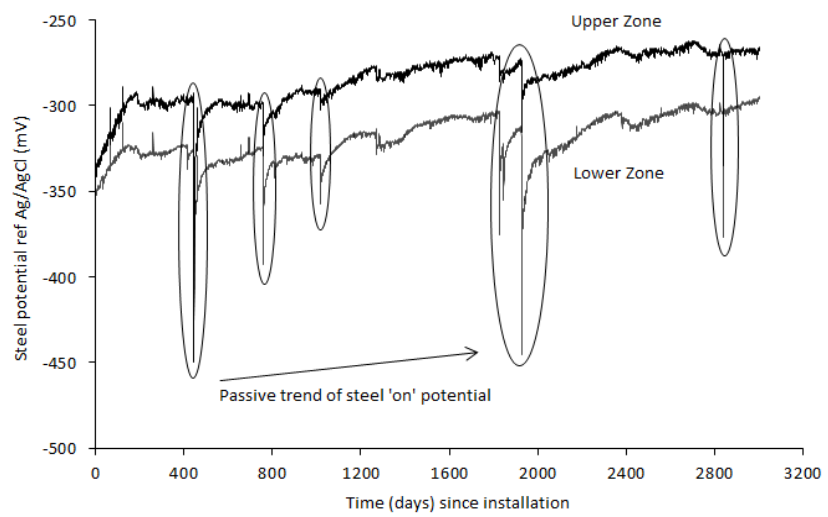

Fig. 6. Change in steel 'ON' potential with time

Similar to system (a), the sudden changes in 'on' potential readings observed at regular intervals (identified in Figure 6) are attributed to flooding of the river.

\subsection{System c): Storth Lane}

Long-term monitoring data is not available for this structure as no remote monitoring equipment was installed at the bridge. The corrosion rate was calculated from a site visit on 23/05/2015 which indicates passive steel conditions for all four of the monitoring zones in the north abutment (Table 2). The 'monitoring zone current (mA)' refers to the current distributed by the four anodes in the monitoring zone, and the 'anode driving voltage $(\mathrm{mV})$ ' refers to the potential difference between the anode and the steel when the system is switched off. This information helps to determine if the anode system has been installed correctly and is still functional.

Table 2 Calculated corrosion rates

\begin{tabular}{|l|c|c|c|c|}
\hline Monitoring Zone & 1 & 2 & 3 & 4 \\
\hline Instant 'off' potential (mV) & $\begin{array}{c}- \\
442\end{array}$ & $\begin{array}{c}- \\
\text { Monitoring zone current }(\mathrm{mA})\end{array}$ & $\begin{array}{c}- \\
466\end{array}$ & $\begin{array}{c}- \\
472\end{array}$ \\
\hline Anode driving voltage (mV) & 223 & 381 & 272 & 191 \\
\hline 'Off' potential (1 hour) (mV) & - & - & - & - \\
\hline Total de-polarisation $(\mathrm{mV})$ & 6 & 1 & 16 & 4 \\
\hline $\begin{array}{l}\text { Cathodic current density } \\
\left.\text { (mA/m }{ }^{2}\right)\end{array}$ & 0.22 & 0.03 & 0.53 & 0.30 \\
\hline Corrosion rate $\left(\mathrm{mA} / \mathrm{m}^{2}\right)$ & $\mathbf{0 . 9 5}$ & $\mathbf{0 . 7 8}$ & $\mathbf{0 . 8 5}$ & $\mathbf{1 . 9 5}$ \\
\hline
\end{tabular}

The system at Storth Lane achieved the recommended criteria for passive steel conditions on the date of this inspection. Also, no visual defects were observed in the area of influence of the hybrid anode zone.

\subsection{System d): Kyle of Tongue}

This particular system does not have a continuous data monitoring system; however, manual readings are taken on an annual basis and these are presented in Figures 7 and 8 . Overall, it can be observed that the corrosion rates have generally remained below the recommended threshold value, apart from a single occurrence. The latter is not considered significant as it was a single event and the magnitude of increase is negligible.

Furthermore, the steel potentials demonstrate a trend towards more positive values which also suggests that the reinforcement is protected and in a passive and benign environment.

\subsection{System e): M69 Junction 2}

Long-term monitoring data was not available for this structure as no remote monitoring equipment was installed on the bridge. Furthermore, due to a 20 minute access limit (without specialist traffic management) it has not been possible to collect full depolarisation data from this bridge. The data collected during a site visit on $23 / 05 / 2014$ shows that the monitored anode zones were effectively distributing a protective current to the steel reinforcement (Table 3). An extended depolarisation test would be beneficial in providing additional performance information and would enable a proper evaluation of the corrosion risk. 


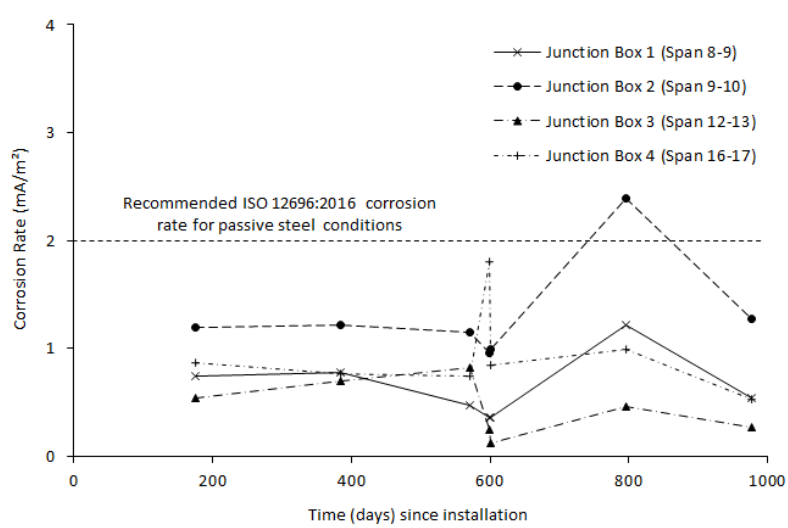

Fig. 7. Change in corrosion rate with time

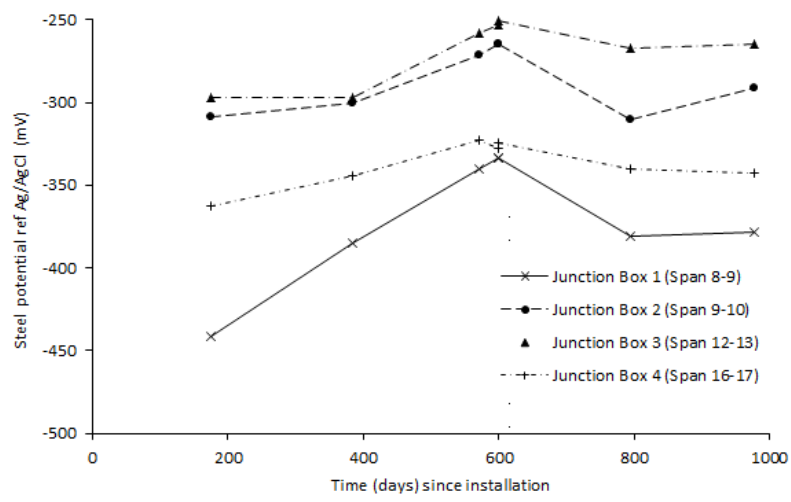

Fig. 8. Change in open circuit steel potential with time

The higher corrosion current on the left zone of abutment 3 (Huncote) may be attributed to wetting of the abutment from the carriageway above, as noted in the visual inspection results. In addition, it has not been possible to undertake a complete depolarisation which may have yielded even lower corrosion current densities.

\subsection{System f): Paston Interchange}

Long-term monitoring data was not available for this structure as no remote monitoring equipment was installed at the bridge. The corrosion rates calculated from the site visit on 09/01/2014 indicated passive steel conditions for all 16 monitoring zones tested (Tables 4 and 5). The total depolarisation time for the West and East piers was 25-26 hours and 23-24 hours respectively.

The low corrosion rates for all 16 monitoring zones, combined with relatively low changes in steel potential between the instant 'off' and 'off' readings (i.e. the total de-polarisation over 24 hours) suggest that corrosion activity is minimal. This structure therefore has a low risk of corrosion initiation.

\section{Discussion}

The aim of this study was to analyse the effectiveness of hybrid anode systems at preventing corrosion initiation of the reinforcing steel using the holistic approach of a condition and corrosion risk assessment. This approach combined the absolute values and alternative performance criteria in ISO 12696:2016 [15], together with an assessment of the overall corrosion risk to a structure from the results of a visual inspection, calculated equivalent section loss of the reinforcing steel over time, and the trends of long-term monitoring data.

Overall, the results of the visual inspections indicated that the areas protected by the hybrid anode systems were found to have no visual defects, and the structures were generally in a good condition.

In some instances, the measured corrosion rates were somewhat higher than the recommended threshold values. While on face value this may appear to be a system failure it ought to be reviewed in overall context. In particular, all instances where a corrosion rate higher than the recommended threshold was calculated, it was observed that the steel 'on' potentials had shifted over time towards more positive values. The resting steel 'on' potentials for systems (a), (b) and (d) have shifted positively by approximately $150-200 \mathrm{mV}, 40-50 \mathrm{mV}$ and $20-60 \mathrm{mV}$ respectively. The highest observed corrosion rate was $3.5 \mathrm{~mA} / \mathrm{m}^{2}$, which equates to an equivalent section loss of reinforcing steel of $3.5 \mathrm{~mm}$ over 1000 years. If this is compared against a typical 120 year design life for a bridge structure then a section loss of approximately $0.4-0.5 \mathrm{~mm}$ should be expected. In addition, all the current outputs were relatively low, with no physical evidence suggesting corrosion (e.g. rust staining, cracking, delamination etc.). These suggest a benign environment with passive reinforcement.

Table 3 M69 Junction 2, recorded site data

\begin{tabular}{|c|c|c|c|c|c|c|}
\hline Abutment & \multicolumn{2}{|c|}{1 (Junction 2) } & \multicolumn{2}{|c|}{2 (Junction 2) } & \multicolumn{2}{|c|}{3 (Huncote) } \\
\hline Zone & Left & Right & Left & Right & Left & Right \\
\hline Instant 'off' potential (mV) & -365 & -322 & -361 & -372 & -414 & -510 \\
\hline Monitoring zone current (mA) & 0.50 & 0.47 & 0.46 & 0.36 & 1.80 & 0.20 \\
\hline Anode driving voltage $(\mathrm{mV})$ & 223 & 214 & 214 & 177 & 247 & 220 \\
\hline Cathodic current density $\left(\mathrm{mA} / \mathrm{m}^{2}\right)$ & 0.67 & 0.63 & 0.61 & 0.48 & 2.40 & 0.27 \\
\hline
\end{tabular}


Table 4 Paston Interchange west piers, calculated corrosion rates

\begin{tabular}{|l|c|c|c|c|c|c|c|c|}
\cline { 2 - 10 } \multicolumn{1}{c|}{} & \multicolumn{4}{c|}{ North West Pier } & \multicolumn{4}{c|}{ South West Pier } \\
\cline { 2 - 10 } \multicolumn{1}{c|}{} & \multicolumn{2}{c|}{ Traffic Face } & \multicolumn{2}{c|}{ Verge Face } & \multicolumn{3}{c|}{ Traffic Face } & \multicolumn{3}{c|}{ Verge Face } \\
\hline Zone & 1 & 2 & 1 & 2 & 1 & 2 & 1 & 2 \\
\hline Instant 'off' potential $(\mathrm{mV})$ & -385 & -400 & -308 & -418 & -408 & -384 & -374 & -383 \\
\hline Monitoring zone current $(\mathrm{mA})$ & 0.12 & 0.54 & 0.01 & 2.67 & 0.73 & 0.91 & 1.00 & 0.11 \\
\hline Depolarised steel potential $(\mathrm{mV})$ & -367 & -343 & -302 & -327 & -302 & -317 & -335 & -337 \\
\hline Total de-polarisation $(\mathrm{mV})$ & 18 & 57 & 6 & 91 & 106 & 67 & 39 & 46 \\
\hline Cathodic current density $\left(\mathrm{mA} / \mathrm{m}^{2}\right)$ & 0.56 & 0.56 & 0.40 & 0.40 & 0.50 & 0.50 & 0.69 & 0.69 \\
\hline Corrosion rate $\left(\mathrm{mA} / \mathrm{m}^{2}\right)$ & 0.79 & 0.21 & 1.73 & 0.07 & 0.07 & 0.15 & 0.42 & 0.34 \\
\hline
\end{tabular}

Table 5 Paston Interchange east piers, calculated corrosion rates

\begin{tabular}{|l|c|c|c|c|c|c|c|c|}
\cline { 2 - 10 } \multicolumn{1}{c|}{} & \multicolumn{4}{c|}{ North East Pier } & \multicolumn{4}{c|}{ South East Pier } \\
\cline { 2 - 10 } \multicolumn{1}{c|}{} & \multicolumn{2}{c|}{ Traffic Face } & \multicolumn{2}{c|}{ Verge Face } & \multicolumn{3}{c|}{ Traffic Face } & \multicolumn{2}{c|}{ Verge Face } \\
\hline Zone & 1 & 2 & 1 & 2 & 1 & 2 & 1 & 2 \\
\hline Instant 'off' potential $(\mathrm{mV})$ & -361 & -346 & -291 & -269 & -355 & -225 & -332 & -279 \\
\hline Monitoring zone current $(\mathrm{mA})$ & 0.88 & 0.46 & 0.04 & 1.12 & 0.07 & 0.01 & 0.04 & 0.19 \\
\hline Depolarised steel potential $(\mathrm{mV})$ & -287 & -317 & -274 & -262 & -347 & -216 & -322 & -264 \\
\hline Total de-polarisation $(\mathrm{mV})$ & 74 & 29 & 17 & 7 & 8 & 9 & 10 & 15 \\
\hline Cathodic current density $\left(\mathrm{mA} / \mathrm{m}^{2}\right)$ & 0.32 & 0.32 & 0.29 & 0.29 & 0.06 & 0.06 & 0.08 & 0.08 \\
\hline Corrosion rate $\left(\mathrm{mA} / \mathrm{m}^{2}\right)$ & 0.08 & 0.27 & 0.44 & 1.08 & 0.19 & 0.17 & 0.21 & 0.14 \\
\hline
\end{tabular}

The collected data shows that the corrosion rates generally remained below the $2 \mathrm{~mA} / \mathrm{m}^{2}$ threshold recommended by ISO 12696:2016, which indicates passive steel conditions [15]. In most of the applications, low magnitude corrosion rates had been calculated over a period of 8 years since the installation of the hybrid systems.

Where remote monitoring is available, extensive site data can be collected and the ongoing performance of hybrid systems can be assessed without the need for site visits, access, or traffic management. Data logging equipment can be programmed to automatically record depolarisation readings at regular intervals, which can be used to plot the change in depolarised steel potential readings and corrosion rates over time. This data is useful when assessing the performance of hybrid anode systems and subsequent corrosion risk.

There is still much debate in industry regarding the adoption of hybrid anodes as an effective corrosion management technique. The collection and publication of long-term performance data of hybrid anodes aims to generate further discussion and interest in the subject domain to overcome existing concerns [17]. The data analysed in this study indicates that the design approach of an initial impressed current phase $\left(50 \mathrm{kC} / \mathrm{m}^{2}\right.$ of steel surface area), followed by an ongoing galvanic phase for the remainder of the anodes design life, has been effective at preventing the reactivation of reinforcement corrosion for up to 8 years.

\section{Conclusions}

It can be concluded that:

- The six structures were found to be generally in good condition, 1 to 8 years after refurbishment works;

- The areas of reinforced concrete protected by the hybrid anode technology were found to have no visual defects associated;

- The results of depolarisation tests, in combination with other evidence, suggests that the hybrid anodes are protecting the steel reinforcement effectively, which is considered to be in a passive condition;

- In the majority of cases, the calculated corrosion rates as set out in ISO 12696:2016 were below the recommended threshold of $2 \mathrm{~mA} / \mathrm{m}^{2}$ for passive reinforcement;

- On some occasions the corrosion rate exceeded the recommended threshold; however, the structures were still assessed as a low corrosion risk based on the absence of any visual defects, steel potential trending towards positive values, and the fact that the recommended corrosion rate was only exceeded in single and isolated events. In addition, in these 
isolated instances, the calculated corrosion rate was only marginally higher than the recommended threshold; all of which provide reassurance of a resultant low corrosion risk.

\section{References}

1. G.K. Glass, A.C. Roberts, N. Davison, Con. Mat. 161, 163-172 (2008)

2. S.P. Holmes, G.D. Wilcox, P.J. Robins, G.K. Glass, Mat. And Corr. 62, 7 (2011)

3. G. Glass, C. Christodoulou, S. Holmes, ICRRR-3 Cape Town, 523-526 (2012)

4. C. Christodoulou, C. Goodier, S. Austin, J. Webb, G. Glass, EUROCORR 2013 Portugal, (2013)

5. C. Christodoulou, R. Kilgour, Corrosion \& Prevention, Brisbane, Australia, Paper 76, 11 (2013)

6. G.K. Glass, N.R. Buenfeld, Corr. Sci. 37, 16431646 (1995)

7. G.K. Glass, A.C. Roberts, N. Davison, Corrosion 2004, NACE, Paper 04332 (2004)

8. G.K. Glass, B. Reddy, L.A. Clark, ICE Con. Mat. 160, 155-164 (2007)
9. R.B. Polder, W.H.A. Peelen, B.T.J. Stoop, E.A.C. Neeft, Mat. And Corr. 62, 2, 105-110 (2011)

10. S.P. Holmes, G.D. Wilcox, P.J. Robins, G.K. Glass, A.C. Roberts, Corr. Sci. 53, 3450-3454 (2011)

11. S.P. Holmes, C. Christodoulou, G.K. Glass, Corrosion \& Prevention 2013, Brisbane, Australia, Paper 133, 11 (2013)

12. C. Christodoulou, C.I. Goodier, S.A. Austin, G.K. Glass, J. Webb, Con. Build. Mat. 50, 300-307 (2014)

13. W. Dodds, C. Christodoulou, C.I. Goodier, S.A. Austin, RILEM International workshop on performance-based specification and control of concrete durability, Zagreb, Croatia, 175-182 (2014)

14. C. Christodoulou, P. Corbett, N. Coxhill, Corrosion \& Prevention 2016, Auckland, New Zealand (2016)

15. British Standards Institution, BS EN ISO 12696 , London: BSI (2016)

16. A.M. Hassanein, G.K. Glass, N.R. Buenfeld, Cem. \& Conc. Comp. 24, 159-167 (2002)

17. W. Dodds, C. Christodoulou, C.I. Goodier, C. Atkins, J. Preston, ICE Con. Mat. 170, 5, 265-270 (2017) 